\title{
Are "Straight to Test" Pathways Always Best for Patients? A Prospective Observational Study of Two-Week-Wait Colorectal Referrals
}

\author{
Frances Mosley $^{1 *}$, Jon R. Ausobsky², John P. Griffith ${ }^{2}$ \\ ${ }^{1}$ Yorkshire and the Humber Deanery, Bradford, UK \\ ${ }^{2}$ Bradford Royal Infirmary, Bradford, UK \\ Email: *Frankiexdude@yahoo.co.uk
}

Received August 27, 2013; revised September 25, 2013; accepted October 3, 2013

Copyright (C) 2013 Frances Mosley et al. This is an open access article distributed under the Creative Commons Attribution License, which permits unrestricted use, distribution, and reproduction in any medium, provided the original work is properly cited.

\begin{abstract}
Aim: Many centres have adopted a straight to test approach to deliver a fast-track service for suspected lower GI cancer. We undertook a prospective comparison between patients having a straight to test (STT) flexible sigmoidoscopy and those attending an outpatient appointment (OPA). The study aimed to determine whether STT reduced diagnostic time without additional investigations. Methods: An observational study of 200 consecutive fast-track colorectal referrals was undertaken. Data collected included: patient demographics, whether STT or OPA, investigations undertaken (including dates) and final diagnosis. Outcomes were compared by adjusted linear regression and logistic regression, for numerical and binary outcomes respectively. Potential confounding factors included were: age, gender and whether NICE referral criteria were achieved. Results: 186 out of 200 referrals attended their appointment, $62 \%(116 / 186)$ went STT and 38\% (70/186) had an OPA. No significant difference was seen in the number of days to final investigation, adjusted coefficient $-3.71,95 \%$ C.I. -8.92 to 1.50 . The STT group had 0.4 more tests per patient, adjusted $95 \%$ C.I. 0.07 to 0.73 , than the OPA group. Significantly more patients in the STT group had a flexible sigmoidoscopy in addition to whole colonic imaging (all modalities), compared to the OPA group, adjusted OR of 93.47 (95\% C.I. 29.26 to 298.54). Conclusion: This study highlights the potential disadvantages of STT flexible sigmoidoscopy for patients referred under the two-week-rule with suspected lower GI cancer. Despite the previously published work highlighting the potential cost and time benefits, it may come at the sacrifice of exposing patients to additional investigations.
\end{abstract}

Keywords: Colorectal Neoplasms (MeSH); Endoscopy; Gastrointestinal (MeSH); Colorectal Surgery (MeSH); 2-Week-Wait; Fast-Track; Straight to Test (No MeSH Term)

\section{Background}

Colorectal cancer causes significant morbidity and mortality worldwide; it is the second most common cancer in England and Wales [1] and the third most common in the US [2] and Canada [3]. The symptoms of colorectal cancer are highly variable but can commonly include a change in bowel habit and rectal bleeding [4]. NICE have produced referral guidelines for patients with suspected lower GI cancer and it is predicted that $80 \%-85 \%$ of those with colorectal cancer fulfil these criteria $[5,6]$. Whilst being highly sensitive, the referral criteria have low specificity with a typical rate of diagnosis between $6 \%$ and 7\% [7-9]. The Cancer Reform Strategy published in 2007 [10] stipulates that these referrals, commonly

\footnotetext{
"Corresponding author.
}

termed fast-track referrals, must be seen by a specialist within 2 weeks. Despite the low rate of colorectal cancer diagnosis, the number of referrals continues to increase and represents a significant workload to most hospitals.

Nationally a variety of strategies have been employed to aid delivery of this diagnostic service. One approach adopted by multiple centres is for the patient to go "straight to test", as opposed to the traditional route of attending an initial outpatient appointment. The use of flexible sigmoidoscopy (along with a full blood count) rather than a method of whole colonic imaging, was advocated by Thompson et al. in 2008 [11], and straight to test flexible sigmoidoscopy has been shown to be an effective method of delivering this diagnostic service [9]. However, not all centres are using straight to test flexible sigmoidoscopy; some are using colonoscopy $[12,13]$ or 
triaging the patient to the most appropriate investigation being dependent on referral information [14].

Previous studies have focused on achieving the twoweek-wait target [9,13], cost-effectiveness [13] or the acceptability of the diagnostic pathway to patients [12]. This study was undertaken at a single centre where some patients went straight to test having a flexible sigmoidoscopy, whilst others had an initial outpatient review. We aimed to determine whether straight to test flexiblesigmoidoscopy led to a shorter diagnostic time without increasing the number of investigations required.

\section{Method}

Data was collected from 200 consecutive "fast-track" referrals to the colorectal department at Bradford Royal Infirmary. All referrals were referred from their G. P. with suspected lower G. I. cancer, under the two-weekwait rule. Data was collected prospectively. Referral details were collected on a weekly basis from the fast-track coordination office. Patient and referral details including: age, gender, date of referral and symptoms at referral were collected from the referral letter. The symptoms stated on the referral letter were used to determine whether the NICE referral criteria had been met. Details regarding the patient's first attendance were collected either directly from the clinic or, where this was not possible the clinic letter was reviewed. All subsequent investigations, including dates, were recorded. To ensure no investigations were missed the patient's clinical notes were reviewed again after they had attended a follow-up appointment. Final diagnosis information was gained from review of the final clinic letter.

Patients were included if they attended for their appointment; patients who cancelled their referral or did not attend on multiple occasions (and were discharged back to their G. P.) were not included. Patients were either seen in a straight to test (flexible sigmoidoscopy) appointment or standard outpatient appointment. Most patients went straight to test; patients were seen in an outpatient for two reasons: the majority were due to a lack of capacity in the straight to test clinic, a small number were triaged, from the referral letter, due to likely frailty (based on their age) or symptoms of anaemia.

\section{Statistical Analysis}

Statistical analysis was undertaken using Stata version 11.0. The two groups of patients were compared for several outcomes: number of tests undertaken, number of days to final investigation, number of patients having flexible sigmoidoscopy, whole colonic imaging (of any modality) and the number having flexible sigmoidoscopy in addition to whole colonic imaging. Potential confounding factors that were included in the regression models were: age, gender and whether fast-track referral criteria were fulfilled (based on referral letter).

The numerical outcomes (number of tests and number of days to final investigation) were analysed by linear regression; the regression being undertaken with and without potential confounding factors. The assumptions of the model were checked by confirming that residuals were normally distributed (histogram) and variance constant across residuals. The remaining outcomes (all binary) were analysed by logistic regression; again being undertaken with and without potential confounding factors. The significance level for all test was set; $p<0.05$.

\section{Results}

200 consecutive referrals were recruited to the study, of these $7 \%(14 / 200)$ were not included as they cancelled their referral or failed to attend on multiple occasions. Of the 14 excluded half (7/14) were initially allocated an outpatient appointment and half a straight to test appointment, those who failed to attend were sent out at least one further outpatient appointment. Of the 186 patients who attended $62.4 \%(116 / 186)$ were first seen in a straight to test flexible sigmoidoscopy appointment and $37.6 \%(70 / 186)$ were seen in an outpatient appointment.

\subsection{Basic Characteristics of Study Population}

The outpatient appointment group were significantly older than those in the straight to test group, at 72.2 and 62.7 years respectively (see Table 1). The gender distribution was similar in both groups, with almost two thirds of referrals being female. Significantly more patients met the NICE referral criteria in the outpatient appointment group, $95.7 \%$ (67/70) compared to $76.5 \%$ (88/115) of the straight to test group, however despite this the rate of colorectal cancer diagnosis was almost identical at 5.7\% $(4 / 70)$ and $6.0 \%$ (7/115) respectively. One referral letter was missing and therefore not included in this analysis.

\subsection{Total Number of Investigations}

The mean number of investigations undertaken in the straight to test group was 2.24 compared to 1.93 in the outpatient appointment group. The un-adjusted and adjustment linear regression analysis were both significant; those in the straight to test group had 0.40 more investigations than the outpatient appointment group (adjusted 95\% C. I. 0.07 to 0.73), p=0.02; see Table 2 .

\subsection{Time to Final Investigation}

The mean number of days to final investigation was 26.44 and 30.74 , for the straight to test and outpatient appointment groups respectively. This difference, adjusted coefficient $-3.71,95 \%$ C.I. -8.92 to 1.50 , however 
Table 1. Basic characteristics of the study participants. Shown for all patients $(n=186)$ and by group, straight to test $(n=116)$ and outpatient appointment $(n=70)$. p-values for statistical comparisons are also given.

\begin{tabular}{ccccc}
\hline & $\begin{array}{c}\text { All attending } \\
\text { patients }(\mathbf{n}=\mathbf{1 8 6})\end{array}$ & $\begin{array}{c}\text { Straight to test } \\
(\mathbf{n}=\mathbf{1 1 6})\end{array}$ & $\begin{array}{c}\text { outpatient appointment } \\
\mathbf{( n = 7 0 )}\end{array}$ & $\begin{array}{c}\text { Statistical test, } \\
\mathbf{p} \text {-value }\end{array}$ \\
\hline Age in years, Mean (SD) & $66.3(14.4)$ & $62.7(13.8)$ & $72.2(13.4)$ & t-test $\mathbf{p}<\mathbf{0 . 0 0 1}$ \\
Proportion female, percent (frequency) & $64.0 \%(119 / 186)$ & $65.5 \%(76 / 116)$ & $61.4 \%(43 / 70)$ & Chi-square $\mathrm{p}=0.6$ \\
$\begin{array}{c}\text { Proportion fulfilling FT criteria, } \\
\text { percent (frequency) }\end{array}$ & $83.8 \%(155 / 185)$ & $76.5 \%(88 / 115)$ & $95.7 \%(67 / 70)$ & Chi-squared $\mathbf{p}=\mathbf{0 . 0 0 1}$ \\
$\begin{array}{c}\text { Proportion diagnosed with CRC, } \\
\text { percent (frequency) }\end{array}$ & $5.9 \%(11 / 186)$ & $6.0 \%(7 / 116)$ & $5.7 \%(4 / 70)$ & Chi-squared $\mathbf{p}=0.9$ \\
\hline
\end{tabular}

Table 2. Linear regression results and descriptive statistics for the number of tests and number of days to final test in the straight to test and outpatient appointment groups; adjusted and unadjusted results are displayed. All Values given to 2 d.p. except p-values given to 1 s.f.

\begin{tabular}{ccccccc}
\hline & $\begin{array}{c}\text { Straight to } \\
\text { test }(\mathbf{n}=\mathbf{1 1 6})\end{array}$ & $\begin{array}{c}\text { Outpatient } \\
\text { appointment }(\mathbf{n}=\mathbf{7 0})\end{array}$ & \multicolumn{2}{c}{ Linear regression, unadjusted } & Adjusted Linear regression \\
\cline { 5 - 6 } & & Coefficient (95\% C.I.) & p-value & Coefficient (95\% C.I.) & p-value \\
\hline $\begin{array}{c}\text { Number of tests, } \\
\text { mean (SD) }\end{array}$ & $2.24(0.79)$ & $1.93(1.38)$ & $0.31(0.00003$ to 0.63$)$ & 0.05 & $0.40(0.07$ to 0.73$)$ & $\mathbf{0 . 0 2}$ \\
$\begin{array}{c}\text { Days to final test, } \\
\text { mean (SD) }\end{array}$ & $26.44(14.64)$ & $30.74(18.70)$ & $-4.30(-9.16$ to 0.56$)$ & 0.08 & $-3.71(-8.92$ to 1.50$)$ & 0.2 \\
\hline
\end{tabular}

did not achieve statistical significance in either the adjusted or unadjusted linear regression analysis; adjusted $\mathrm{p}$ $=0.2$.

\subsection{Investigations Undertaken}

\subsubsection{Flexible Sigmoidoscopy}

The types of investigations undertaken in the two groups are compared in Table 3. 96.6\% (112/116) of those who went straight to test had a flexible sigmoidoscopy compared to just $11.4 \%(8 / 70)$ of those who went to outpatient appointment. This difference is highly significant (p $<0.001$ ), with an adjusted odds ratio of 222.93 (95\% C.I. 57.16 to 869.44$)$.

\subsubsection{Whole Colonic Imaging}

CT colonography, colonoscopy and barium enema are three different methods of evaluating the whole colon. In both groups the majority of patients required full colonic imaging, there was, however, a difference observed between the two groups. $86.2 \%(100 / 116)$ of those in the straight to test and $71.4 \%(50 / 70)$ of the outpatient appointment group required whole colon imaging. This difference was statistically significant $(\mathrm{p}=0.004)$ with an adjusted OR 3.48 (95\% C.I. 1.50 to 8.11). Table 4 provides a breakdown of the types of whole colonic imaging used in each group.

\subsubsection{Whole Colonic Imaging in Addition to Flexible Sigmoidoscopy}

The proportion of patient having flexible sigmoidoscopy in addition to a modality of whole colonic imaging was evaluated. $83.6 \%(97 / 116)$ of those in the straight to test group had both a flexible sigmoidoscopy and whole colonic imaging compared to just $7.1 \%(5 / 70)$ of the outpatient appointment group. This difference was highly significant with an adjusted OR of 93.47 (95\% C.I. 29.26 to 298.54$), \mathrm{p}<0.001$.

\section{Discussion}

Straight-to-test pathways have been widely adopted across the UK for investigation of new patient referrals, including fast-track referrals with suspected lower G. I. cancer $[8,13,14]$. To our knowledge this is the first study to compare straight to test with conventional outpatient review for the number and type of investigations undertaken. The principle of straight to test is that it reduces the number of steps taken, by removing the initial outpatient review. Previous studies have been able to demonstrate that this produces a significant time benefit; a recent study observed a reduction in median time to treatment of 6 days [8]. We evaluated time to final investigation, the mean was 4 days shorter for the straight to test group, this difference failed to achieve statistical significance however the study was under-powered to detect a difference of this size. Additionally, a difference of this magnitude may not be considered important by patients and does not affect the delivery of 31 and 62 day targets. In addition to failing to demonstrate a time advantage we found that the straight to test group had more investigations than those first attending an outpatient appointment. 
Table 3. Logistic regression results for the investigations undertaken in the straight to test and outpatient appointment groups; adjusted and unadjusted results are displayed. Percentages given to 1 d.p., OR and C.I. given to 2 d.p., and p-values given to 1 s.f.

\begin{tabular}{|c|c|c|c|c|c|c|}
\hline & \multirow{2}{*}{$\begin{array}{l}\text { Straight to } \\
\text { test }(n=116)\end{array}$} & \multirow{2}{*}{$\begin{array}{c}\text { Outpatient } \\
\text { appointment }(n=70)\end{array}$} & \multicolumn{2}{|c|}{ Logistic regression, unadjusted } & \multicolumn{2}{|c|}{ Adjusted Logistic regression } \\
\hline & & & OR (95\% C.I.) & p-value & OR (95\% C.I.) & p-value \\
\hline $\begin{array}{l}\text { Flexible sigmoidoscopy, } \\
\text { percent (frequency) }\end{array}$ & $\begin{array}{c}96.6 \% \\
(112 / 116)\end{array}$ & $\begin{array}{l}11.4 \% \\
(8 / 70)\end{array}$ & $\begin{array}{c}217 \\
\text { (62.82 to } 749.63)\end{array}$ & $<0.001$ & $\begin{array}{c}222.93 \\
(57.16 \text { to } 869.44)\end{array}$ & $<0.001$ \\
\hline $\begin{array}{c}\text { Whole colonic imaging, } \\
\text { percent (frequency) }\end{array}$ & $\begin{array}{c}86.2 \% \\
(100 / 116)\end{array}$ & $\begin{array}{l}71.4 \% \\
(50 / 70)\end{array}$ & $\begin{array}{c}2.5 \\
(1.19 \text { to } 5.24)\end{array}$ & 0.02 & $\begin{array}{c}3.48 \\
(1.50 \text { to } 8.11)\end{array}$ & 0.004 \\
\hline $\begin{array}{l}\text { Flexi-sigmoidoscopy and } \\
\text { Whole colonic imaging, } \\
\text { percent (frequency) }\end{array}$ & $\begin{array}{c}83.6 \% \\
(97 / 116)\end{array}$ & $\begin{array}{l}7.1 \% \\
(5 / 70)\end{array}$ & $\begin{array}{c}66.37 \\
\text { (23.60 to } 186.65)\end{array}$ & $<0.001$ & $\begin{array}{c}93.47 \\
\text { (29.26 to } 298.54)\end{array}$ & $<0.001$ \\
\hline
\end{tabular}

Table 4. Methods of whole colonic imaging, shown for all patients $(n=186)$ and by group, straight to test $(n=116)$ and outpatient appointment $(n=70)$.

\begin{tabular}{lccc}
\hline Method of Whole colonic imaging & All attending patients $(\mathbf{n}=\mathbf{1 8 6})$ & Straight to test $(\mathbf{n}=\mathbf{1 1 6})$ & outpatient appointment $(\mathbf{n}=\mathbf{7 0})$ \\
\hline Colonoscopy, percent (frequency) & $53.8 \%(100 / 186)$ & $51.7 \%(60 / 116)$ & $57.1 \%(40 / 70)$ \\
Barium enema, percent (frequency) & $19.9 \%(37 / 186)$ & $29.3 \%(34 / 116)$ & $4.3 \%(3 / 70)$ \\
CT Colonography, percent (frequency) & $13.4 \%(25 / 186)$ & $8.6 \%](10 / 116)$ & $21.4 \%(15 / 70)$ \\
\hline
\end{tabular}

There were some expected differences in the patterns of investigation between the two groups. Significantly more of the straight to test group had a flexible sigmoidoscopy and in addition more had a barium enema. The reason a barium enema was more often selected in these patients, than those attending for outpatient review, is a reflection that all these patients had already had their left colon examined by flexible sigmoidoscopy $[9,15]$.

There were differences between the two groups of patients; the outpatient appointment group were significantly older and with a higher proportion of patients meeting the referral criteria. With these differences adjusted for there was a significant difference in the number requiring whole colonic imaging, with more of those in the straight to test group having this; this difference is not readily explicable in this study.

The most significant finding in terms of the pattern of investigation was that $83.6 \%(97 / 116)$ of the straight to test group had flexible sigmoidoscopy in addition to whole colonic imaging compared to just $7.1 \%(5 / 70)$ of the outpatient appointment group. Given that most patients were judged by their clinician to need whole colonic imaging, it would appear that the majority of the patients in the straight to test group had a superfluous flexible sigmoidoscopy. With the low specificity of the referral criteria this requirement for whole colonic imaging in a significant proportion of patients seems almost inevitable. Whilst it had been suggested that whole colon imaging could be limited to those with iron deficiency anaemia, this is not a universally accepted policy. Whole colon imaging will not only identify a number of right sided malignancies that may otherwise have been missed, but also facilitates the diagnosis of non-malignant pathology $[11,16]$.

Straight to test may also represent a disadvantage to the provider, in particular the demand for endoscopic investigations. We observed that a significant number of those having a flexible sigmoidoscopy went on to have a colonoscopy. If all patients attended an initial outpatient review the total number of endoscopic tests would be reduced; this may allow the provider to reduce the waiting times for all investigations.

The major strength of this study was the inclusion of consecutive referrals with no exclusion criteria. We observed similar age and gender characteristics to the previous single centre studies identified $[9,13,17]$. The rate of colorectal cancer diagnosis at $6 \%(11 / 186)$ was in line with the rates previously reported (between $6 \%$ and $7 \%$ [7-9]). A weakness of this study is the non-random allocation of patients; we have attempted to account for the potential differences between the groups by adjusting for age, gender and whether the referral criteria were fulfilled. Despite this there may have been other inherent differences between the two groups which have not been accounted for within the analysis.

\section{Conclusion}

Overall this study has highlighted that there may be a limited benefit to patients in following a straight to test (flexible sigmoidoscopy) pathway. In this study patients underwent more investigations and were more likely to 
have two modes of endoscopic evaluation with little significant benefit in terms of the time to complete investigation. Despite the previously published work highlighting the potential cost and time benefits of such a pathway, this may come at the sacrifice of exposing patients to additional and potentially unnecessary investigations. Straight to test (STT) may also represent a disadvantage to the provider, with an increased demand on resources, particularly endoscopy services.

\section{REFERENCES}

[1] M. Quinn, P. Babb, A. Brock, L. Kirby and J. Jones, "Cancer Trends in England and Wales 1950-1999," The Stationery Office, London, 2001.

[2] American Cancer Society website, "Cancer Facts \& Figures," 2001. www.cancer.org

[3] Canadian Cancer Society Website, "Canadian Cancer Statistics," 2001. www.cancer.ca

[4] N. Keddie and A. Hargreaves, "Symptoms of Carcinoma of the Colon and Rectum," Lancet, Vol. 2, No. 7571, 1968, pp. 749-750.

http://dx.doi.org/10.1016/S0140-6736(68)90950-1

[5] Department of Health, "Referral Guidelines for Suspected Cancer," 2005.

http://publications.nice.org.uk/referral-guidelines-for-susp ected-cancer-cg27

[6] National Institute of Clinical Excellence (NICE), "Improving outcomes in Colorectal Cancer," MIT Press, Cambridge, 2004.

[7] E. Leung, J. Grainger, N. Bandla and L. Wong, "The Effectiveness of the '2-Week Wait' Referral Service for Colorectal Cancer," International Journal of Clinical Practice, Vol. 64, No. 12, 2010, pp. 1671-1674. http://dx.doi.org/10.1111/j.1742-1241.2010.02505.x

[8] S. Mukherjee, G. Fountain, M. Stalker, J. Williams, T. R. C. Porrett and P. J. Lunniss, "The 'Straight to Test' Initiative Reduces both Diagnostic and Treatment Waiting Times for Colorectal Cancer: Outcomes after 2 Years," Colorectal Disease: The Official Journal of the Association of Coloproctology of Great Britain and Ireland, Vol. 12, No. 10, 2010, pp. e250-e254.

[9] R. A. Smith, et al., "Outcomes in 2748 Patients Referred to a Colorectal Two-Week Rule Clinic," Colorectal Disease: The Official Journal of the Association of Coloproctology of Great Britain and Ireland, Vol. 9, No. 4, 2007, pp. 340-343.

[10] Department of Health, "UK Cancer Reform Strategy," 2007.

http://webarchive.nationalarchives.gov.uk/+/www.dh.gov .uk/en/Healthcare/Cancer/DH_091120

[11] M. R. Thompson, et al., "Flexible Sigmoidoscopy and Whole Colonic Imaging in the Diagnosis of Cancer in Patients with Colorectal Symptoms," The British Journal of Surgery, Vol. 95, No. 9, 2008, pp. 1140-1146. http://dx.doi.org/10.1002/bjs.6234

[12] K. Maruthacalam, S. Noblett, S. Chaudri, E. Stoker and A. Horgan, "Two Week Rule Cancer Referral: Direct Access Colonoscopy vs Out-Patient Appointment, a Prospective Audit and Satisfaction Survey," Colorectal Diseases, Vol. 6, No. 1, 2004, p. 49.

[13] A. D. Beggs, R. D. Bhate, S. Irukulla, M. Achiek and A. M. Abulafi, "Straight to Colonoscopy: The Ideal Patient Pathway for the 2-Week Suspected Cancer Referrals?" Annals of the Royal College of Surgeons of England, Vol. 93, No. 2, 2011, pp. 114-119.

[14] D. M. Hemingway, J. Jameson and M. J. Kelly, "Straight to Test: Introduction of a City-Wide Protocol Driven Investigation of Suspected Colorectal Cancer," Colorectal disease: The Official Journal of the Association of Coloproctology of Great Britain and Ireland, Vol. 8, No. 4, 2006, pp. 289-295.

[15] D. M. Hough, et al., "Colon Cancer Detection: An Algorithm Using Endoscopy and Barium Enema," Clinical Radiology, Vol. 49, No. 3, 1994, pp. 170-175. http://dx.doi.org/10.1016/S0009-9260(05)81769-6

[16] S. Rai and D. Hemingway, "Iron Deficiency AnaemiaUseful Diagnostic Tool for Right Sided Colon Cancers?" Colorectal Disease: The Official Journal of the Association of Coloproctology of Great Britain and Ireland, Vol. 7, No. 6, 2005, pp. 588-590.

[17] M. M. Aljarabah, N. R. Borley, A. J. Goodman and J. M. D. Wheeler, "Referral Letters for 2-Week Wait Suspected Colorectal Cancer Do Not Allow a 'Straight-to-Test' Pathway," Annals of the Royal College of Surgeons of England, Vol. 91, No. 2, 2009, pp. 106-109. http://dx.doi.org/10.1308/003588409X359114 